\title{
Assessment of Knowledge and Practices of Staff Nurses towards Infectious Diseases Isolation Precautions in Tertiary Care Hospitals: A Multi-Center Study \\ ${ }^{1,2}$ Moustapha A. Ramadan, ${ }^{1,3}$ Samar S. Morsi, ${ }^{1,4}$ Amira M. Sultan, ${ }^{1}$ Mariam A. Alfadhli, ${ }^{1,5}$ Wafaa S. Hamza \\ ${ }^{1}$ Infection Control Directorate, Ministry of Health, Kuwait, ${ }^{2}$ Community Medicine Department, Faculty of Medicine, Alexandria University, Egypt, ${ }^{3}$ Department of Microbiology and Immunology, Faculty of Medicine, Zagazig University, Egypt, ${ }^{4}$ Department of Medical Microbiology and Immunology, Faculty of Medicine, Mansoura University, Egypt, ${ }^{5}$ Department of Public Health and Community Medicine, Faculty of Medicine, Assiut University, Egypt.
}

\begin{abstract}
Background: Compliance with the evidence-based isolation precaution guidelines is essential to prevent the spread of infectious diseases among hospitalized patients and its ensuing complications. Objectives: This study aimed to assess the nurses' knowledge towards the infectious diseases' isolation precautions in governmental tertiary care hospitals and to identify the relationship between nurse's characteristics concerning their knowledge and practices. Method: A cross-sectional study was conducted in ten tertiary care hospitals using a self-administrated questionnaire to collect nurses' characteristics and to assess their knowledge level. Nurses' practices were evaluated using an observation checklist Univariate, bivariate, and logistic regression analysis were applied. Results: The study revealed that $35.8 \%$ of nurses had a good knowledge regarding isolation precautions and $41.6 \%$ had good practices score. Some demographic variables inclined Nurses' knowledge; age, gender, education, and experience. While their practice score was affected by; gender, work experience, and unit of work (ICU vs. non- ICU). A statistically significant positive correlation was revealed between the overall knowledge score and the overall practice score of nurses regarding adherence to the infectious diseases isolation precautions $(\mathrm{r}=0.3)$. Participants' education and duration of working experience were the significant predictors for higher knowledge scores $(p<0.05)$. Conclusion: The tailored multi-modal training approach can improve nurses' knowledge and promote their experiences towards isolation precautions.
\end{abstract}

Keywords: Prevention, Isolation precaution, Infection control, Nurse training.

Corresponding Authors: Moustapha A. Ramadan E-mail: ficas_alex@yahoo.fr

\section{Introduction}

The burden of infectious diseases fell dramatically during the last century, largely due to immunization and improvement in sanitation. ${ }^{1}$ Despite this epidemiological transition, researchers believe in the resurgence of infectious diseases. $^{2}$ Thus infectious diseases continue to be a main public health concern and problem. They are responsible for an increase in hospital stay, extra services required during hospitalization and account for about 12 million deaths globally. ${ }^{3-5}$

Healthcare workers (HCWs) compliance and mainly nurses by following the infection control precautions are known as effective means to prevent and control diseases transmission not only among patients but also among HCWs and to the environment. ${ }^{6-7}$

The nurses are the key members of providing continuous care for patients. Their knowledge and adherence to all 
measures associated with disease transmission prevention and control are considered as a top priority. ${ }^{8}$ Several studies were conducted in the region to assess the level of HCWs' knowledge and practice focused on type-specific or disease-specific isolation precautions particularly against the emerging infectious diseases. ${ }^{9-11}$ These researches concluded that in addition to regular education and training activities, monitoring practices comply with the evidence-based isolation guidelines is a crucial element for patients' safety and an important element to assess the need of HCWs for orientation and training regarding the isolation precautions. ${ }^{9-12}$ No similar study was conducted in the state of Kuwait; therefore the authors would like to conduct this study with the purpose to assess the nurses level of knowledge and practices towards different types of infectious diseases isolation precautions in multiple governmental tertiary care centers and to identify the relationship between the nurses' characteristics in relation to their knowledge and practices.

\section{Method}

A cross-sectional study design conducted over six months from April to September 2019. The data were collected from 10 tertiary care governmental centers affiliated to the ministry of health in the state of Kuwait. These centers include the following non ICU departments; medical, orthopedics, cardiology, cardiothoracic, otolaryngology, ophthalmology, obstetrics and gynecology, pediatric surgery, neonatal, organ transplant, nephrology and burn units. In addition to these wards there are intensive care units for different specialties in each hospital. The total bed capacity in these hospitals is 1843 bed.

The nurses (males \& females) employed at the Kuwait Ministry of Health tertiary care hospitals.

Currently working nurses in the study hospitals for more than one year with full-time employment and providing direct patient care for in-patient departments (wards and ICUs) were eligible for this study. The number of those eligible nurses was approximately 1430 .

The researchers obtained the number of nurses working in the ten tertiary care centers from the National Health Information and Statistics annual report. ${ }^{13}$ Then added up these numbers to get the total targeted population frame from which the sample was drawn. The sample size was calculated using EpiInfo program version number 7 using the sampling technique for cross-sectional study with power $80 \%$ and confidence interval 95\%. The anticipated knowledge percentage used in the calculation is $50 \%$, this procedure yielded a sample of 303 nurses.

The recruitment of nurses in each hospital was based upon the previous calculated representative percentage of the nurse's number from the total targeted population. Thereafter the sample from each hospital was drawn using a systematic random sample technique from the list of nurses working in the inpatients departments and providing direct care for patients with infectious diseases. Nurses were invited, explained the study objectives, assured the confidentiality of data and consented to participate in the study.

The following research tools used to collect data: $A$ self-administrated questionnaire used to describe the nurses' characteristic including nurse's age, gender, marital status, hospital name, department of work (ICU or nonICU), nursing degree of education, work experience in years. In addition to questions concerning receiving any training regarding infection control isolation precautions in the last year or not, and the availability of the isolation precautions guidelines in their departments. 
The nurses' knowledge assessed covered the following domains: Patient placement, performing hand hygiene and the use of appropriate personal protective equipment (PPE), methods of care in regards to patient equipment, the process of waste management and precautions taken during patient transfer. The knowledge assessment was done using twenty four questions; each question has a group of answers and only one answer is correct. The researchers counted one point for each correct answer (when the respondent's answer to the question was in agreement with the Centers for Disease Control and Prevention (CDC) isolation precaution recommendations') [14]. The wrong answer or I don't know the answer was taking zero. All the scores for the correct answers were added up to obtain a total knowledge score for each participant. The knowledge scores were classified into three groups; the first one who had answered less than $50 \%$ of the questions correctly, the second group who had correct response to $50 \%$ of the questions but less than $80 \%$, the last group who answered $80 \%$ or more of questions accurately. ${ }^{15}$

Observation checklist: Practices
assessment was done using an observation checklist. The checklist domains were similar to the knowledge domains and agreed with CDC isolation precautions guidelines. ${ }^{14}$ The nurse practices evaluated using a total of twenty four statements with answers; yes, no or not observed. The not observed domain removed from the total elements during the analysis. The results of the practice score were classified into three groups; the first group had less of $50 \%$ of the observed practice done in the recommended way, the second group had $50 \%$ or more and less than $80 \%$ of the observed practice done in the proper manner, the last group had at least $80 \%$ of the observed practice done in the appropriate way. ${ }^{16}$
Validity and reliability of the study tools: The research tools were revised by professors of public health and community medicine experienced in the community and public health researches. The reliability of the questionnaire and checklist statements was assessed by calculating Cronbach's Alpha which was 0.72 and 0.81 for nurse's knowledge and practices respectively.

A pilot study was accomplished to test the study instruments and refine the methodology. It was applied on 20 staff nurses, working in the same settings, using the same data collection and analysis techniques to determine the clarity of questions, response, the time needed to complete the questionnaire and accomplishment of data collection technique. The nurses shared in the pilot were not part of the study sample and their data excluded from the analysis of the study.

Assigned infection control nurses in the studied hospitals distributed the questionnaires and completed the observation checklist. The researchers provided a training session for them before they started the collection of data. The training included a briefing of the research methods and an explanation of how to complete the observation checklist to ensure the accuracy and consistency of data.

Before the beginning of the study and after explaining the objectives of the research and ensuring confidentiality of the data, all participants in each hospital signed a consent form. Each consented nurse received a self-administered questionnaire, which was distributed to be filled out to collect their characteristics and knowledge towards infectious diseases isolation precautions. The questionnaires were collected after 30 minutes. Afterwards, nurses' practice were evaluated without prior notice and data collected by a concealed observation technique during their regular care. The 
participating nurses were observed during giving direct care for patients under different isolation precautions.

\section{Ethical consideration}

The necessary official approval obtained from the Ministry of Health Joint Committee for the protection of human subjects in research under number (997/ 5 March 2019). Informed consent was obtained from all participating staff nurses. Participants were assured about the confidentiality of the given information. All data were coded, entered and analyzed anonymously.

\section{Statistical analysis}

Data was presented using frequency, percentage, and mean \pm SD. Binary logistic regression analysis and Spearman's correlation coefficient applied to examine the relationship between the participant's knowledge, practices, and different characteristics. A Chi-square test used to analyze paired qualitative data. Statistical significance was set at $p$-value $(<0.05)$. Statistical analysis was done using SPSS version 19 statistical software package (IBM, Chicago, IL, USA).

\section{Results}

Out of the sample of 303 nurses a total of 243 of them completed both questionnaire and the checklists, with a response rate of $80.2 \%$. The analysis of the participants' variables revealed that the majority of the nurses were females $72.4 \%$, their mean age was $36.21 \pm 6.76$ years, $60.9 \%$ had bachelor's degree, $32.9 \%$ worked in the intensive care unit, and $76.9 \%$ had been working for 5 years and more, and $72.1 \%$ of the nurses participated in the study received training about isolation precautions in the last year. The isolation precautions guidelines were reported available by $94.7 \%$ of respondents (Table 1 ).

Figure (1) shows the distribution of the participant's scores in the different knowledge domains, patient placement, hand hygiene and PPE, patient equipment, waste management, and patient transfer.

Table (1): Characteristics of The Participant Nurses in The Studied Tertiary Care Hospitals

\begin{tabular}{|c|c|c|}
\hline Nurses Characteristics & $\begin{array}{l}\text { No. } \\
\text { (243) }\end{array}$ & $\%$ \\
\hline \multicolumn{3}{|l|}{ Age: (years) } \\
\hline$<35$ & 120 & 49.4 \\
\hline $35-40$ & 65 & 26.7 \\
\hline$>40$ & 58 & 23.9 \\
\hline Mean \pm SD & $36.2 \pm 6.7$ & \\
\hline (Range) & $23.0-65.0$ & \\
\hline \multicolumn{3}{|l|}{ Gender: } \\
\hline Male & 67 & 27.6 \\
\hline Female & 176 & 72.4 \\
\hline \multicolumn{3}{|l|}{ Education: } \\
\hline Nursing diploma & 96 & 39.5 \\
\hline Bachelor & 147 & 60.5 \\
\hline \multicolumn{3}{|l|}{ Marital status: } \\
\hline Single & 24 & 9.9 \\
\hline Married & 219 & 90.1 \\
\hline \multicolumn{3}{|l|}{ Area: } \\
\hline ICU & 80 & 32.9 \\
\hline Non-ICU & 163 & 67.1 \\
\hline \multicolumn{3}{|l|}{$\begin{array}{l}\text { Duration of experience } \\
\text { in the study hospital: }\end{array}$} \\
\hline$<5$ & 59 & 24.3 \\
\hline $5-10$ & 100 & 41.1 \\
\hline$>10$ & 84 & 34.6 \\
\hline Mean \pm SD & $9.37 \pm 5.90$ & \\
\hline (Range) & $\begin{array}{ll}(1.0 & - \\
40.0) & \end{array}$ & \\
\hline $\begin{array}{l}\text { Previous training on } \\
\text { isolation precautions in } \\
\text { the last year }\end{array}$ & 187 & 77.0 \\
\hline $\begin{array}{l}\text { Isolation precautions } \\
\text { guidelines is available }\end{array}$ & 230 & 94.7 \\
\hline
\end{tabular}

Around two-thirds of the participants responded properly to at least $80 \%$ of knowledge questions concerning patients transfer, patient's equipment and hand hygiene \& use of PPE. While the percentage of participants with knowledge score of $80 \%$ or more regarding waste management was only $10 \%$.

Looking at the overall knowledge score; it was found that $35.8 \%$ of the participants fell in the third group (correct knowledge $80 \%$ or more). 
Additionally, the analysis of the knowledge domain scores concerning participants' characteristics variables

indicates that there is a statistically significant difference

Table (2): The relationship between participant nurses 'knowledge level and their characteristics

\begin{tabular}{|c|c|c|c|c|c|c|c|c|}
\hline \multirow{3}{*}{ Characteristics } & \multicolumn{6}{|c|}{ Knowledge level } & \multirow{3}{*}{$\mathbf{X}^{2}$} & \multirow{3}{*}{ P-value } \\
\hline & \multicolumn{2}{|c|}{$<50$} & \multicolumn{2}{|c|}{$50-<80$} & \multicolumn{2}{|c|}{$\geq 80$} & & \\
\hline & No. & $\%$ & No. & $\%$ & No. & $\%$ & & \\
\hline \multicolumn{7}{|l|}{ Age: (years) } & \multirow{4}{*}{16.12} & \multirow{4}{*}{$0.003 *$} \\
\hline$<35$ & 19 & 15.8 & 72 & 60.0 & 29 & 24.2 & & \\
\hline $35-40$ & 5 & 7.7 & 29 & 44.6 & 31 & 47.7 & & \\
\hline$>40$ & 3 & 5.2 & 28 & 48.3 & 27 & 46.6 & & \\
\hline \multicolumn{7}{|l|}{ Gender: } & \multirow{3}{*}{6.74} & \multirow{3}{*}{$0.034 *$} \\
\hline Male & 13 & 19.4 & 34 & 50.7 & 20 & 29.9 & & \\
\hline Female & 14 & 8.0 & 95 & 54.0 & 67 & 38.1 & & \\
\hline \multicolumn{7}{|l|}{ Education: } & \multirow{3}{*}{19.85} & \multirow{3}{*}{$0.000^{*}$} \\
\hline Nursing diploma & 20 & 20.8 & 53 & 55.2 & 23 & 24.0 & & \\
\hline Bachelor & 7 & 4.8 & 76 & 51.7 & 64 & 43.5 & & \\
\hline \multicolumn{7}{|l|}{ Marital status: } & \multirow{3}{*}{2.85} & \multirow{3}{*}{0.240} \\
\hline Single & 4 & 16.7 & 15 & 62.5 & 5 & 20.8 & & \\
\hline Married & 23 & 10.5 & 114 & 52.1 & 82 & 37.4 & & \\
\hline \multicolumn{7}{|l|}{ Area: } & \multirow{3}{*}{3.53} & \multirow{3}{*}{0.171} \\
\hline ICU & 5 & 6.3 & 42 & 52.5 & 33 & $\overline{41.3}$ & & \\
\hline Non-ICU & 22 & 13.5 & 87 & 53.4 & 54 & 33.1 & & \\
\hline
\end{tabular}

\section{Duration of experience in}

the current hospital:

\begin{tabular}{lrrrrrrrr}
$<5$ & 12 & 20.3 & 37 & 62.7 & 10 & 16.9 & 29.22 & $0.000^{*}$ \\
$5-10$ & 12 & 12.0 & 58 & 58.0 & 30 & 30.0 & & \\
$>10$ & 3 & 3.6 & 34 & 40.5 & 47 & 56.0 & & \\
\hline
\end{tabular}

Previous training on isolation

precautions in the last year:

$\begin{array}{lrrrrrrr}\text { Yes } & 24 & 12.8 & 99 & 52.9 & 64 & 34.2 & 2.74 \\ \text { No } & 3 & 5.4 & 30 & 53.6 & 23 & 41.1 & \end{array}$

between their knowledge in terms of variables such as age, gender, education level, and duration of working experience $(p<0.05)$ (Table 2).

Figure (2) shows the distribution of the participant's scores in the different practice domains; patient placement, hand hygiene and PPE, patient equipment, waste management, and patient transfer. The majority of studied nurses showed a correct practice in at least of $80 \%$ of the observation regarding the patient equipment and patient transfer. On the other hand only less than one third had a proper practice in at least $80 \%$ of the observation concerning the patient placement. In the current research, the analysis identified that
$41.6 \%$ of the participants were adherent to $80 \%$ or more of the observed practices. Moreover, the investigation of the participants' practice domain scores concerning their characteristics revealed a statistically significant difference between their practice scores about gender, duration of working experience, type of isolation and working in ICU vs. non -ICU settings $(p<0.05)$ (Table 3$)$.

Spearman's correlation coefficient was applied to compute the relationship between knowledge score and participant characteristics variables. It revealed a statistically significant positive correlation between the knowledge score and both participants' age and duration of the experience $r=0.23 \quad \& \quad 0.33$ 
respectively with $p$-value $(<0001)$.

Additionally, the relationship between

characteristics variables showed a practice score and participants

statistically significant positive

Table (3): The relationship between participant nurses' practice level and their characteristics

\begin{tabular}{|c|c|c|c|c|c|c|c|c|}
\hline \multirow{3}{*}{ Characteristics } & \multicolumn{6}{|c|}{ Practices level } & \multirow{3}{*}{$X^{2}$} & \multirow{3}{*}{ P-value } \\
\hline & \multicolumn{2}{|c|}{$<\mathbf{5 0}$} & \multicolumn{2}{|c|}{$50-<80$} & \multicolumn{2}{|c|}{$\geq 80$} & & \\
\hline & No. & $\%$ & No. & $\%$ & No. & $\%$ & & \\
\hline \multicolumn{9}{|l|}{ Age: (years) } \\
\hline$<35$ & 24 & 20.0 & 47 & 39.2 & 49 & 40.8 & \multirow{3}{*}{9.01} & \multirow{3}{*}{0.061} \\
\hline $35-40$ & 5 & 7.7 & 32 & 49.2 & 28 & 43.1 & & \\
\hline$>40$ & 4 & 6.9 & 30 & 51.7 & 24 & 41.4 & & \\
\hline \multicolumn{9}{|l|}{ Gender: } \\
\hline Male & 18 & 26.9 & 21 & 31.3 & 28 & 41.8 & \multirow{2}{*}{15.79} & \multirow[t]{2}{*}{$0.000^{*}$} \\
\hline Female & 15 & 8.5 & 88 & 50.0 & 73 & 41.5 & & \\
\hline \multicolumn{9}{|l|}{ Education: } \\
\hline Nursing diploma & 13 & 13.5 & 44 & 45.8 & 39 & 40.6 & \multirow[t]{2}{*}{0.07} & \multirow[t]{2}{*}{0.967} \\
\hline Bachelor & 20 & 13.6 & 65 & 44.2 & 62 & 42.2 & & \\
\hline \multicolumn{9}{|l|}{ Marital status: } \\
\hline Single & 3 & 12.5 & 14 & 58.3 & 7 & 29.2 & \multirow[t]{2}{*}{2.09} & \multirow[t]{2}{*}{0.352} \\
\hline Married & 30 & 13.7 & 95 & 43.4 & 94 & 42.9 & & \\
\hline \multicolumn{9}{|l|}{ Area: } \\
\hline ICU & 4 & 5.0 & 39 & 48.8 & 37 & 46.3 & \multirow[t]{2}{*}{7.50} & \multirow[t]{2}{*}{$0.024^{*}$} \\
\hline Non-ICU & 29 & 17.8 & 70 & 42.9 & 64 & 39.3 & & \\
\hline \multicolumn{9}{|l|}{$\begin{array}{l}\text { Duration of Work in } \\
\text { the current hospital: }\end{array}$} \\
\hline$<5$ & 17 & 28.8 & 26 & 44.1 & 16 & 27.1 & \multirow[t]{3}{*}{17.35} & \multirow[t]{3}{*}{$0.002 *$} \\
\hline $5-10$ & 9 & 9.0 & 44 & 44.0 & 47 & 47.0 & & \\
\hline$>10$ & 7 & 8.3 & 39 & 46.4 & 38 & 45.2 & & \\
\hline
\end{tabular}

Previous training on isolation

precautions in the last year:

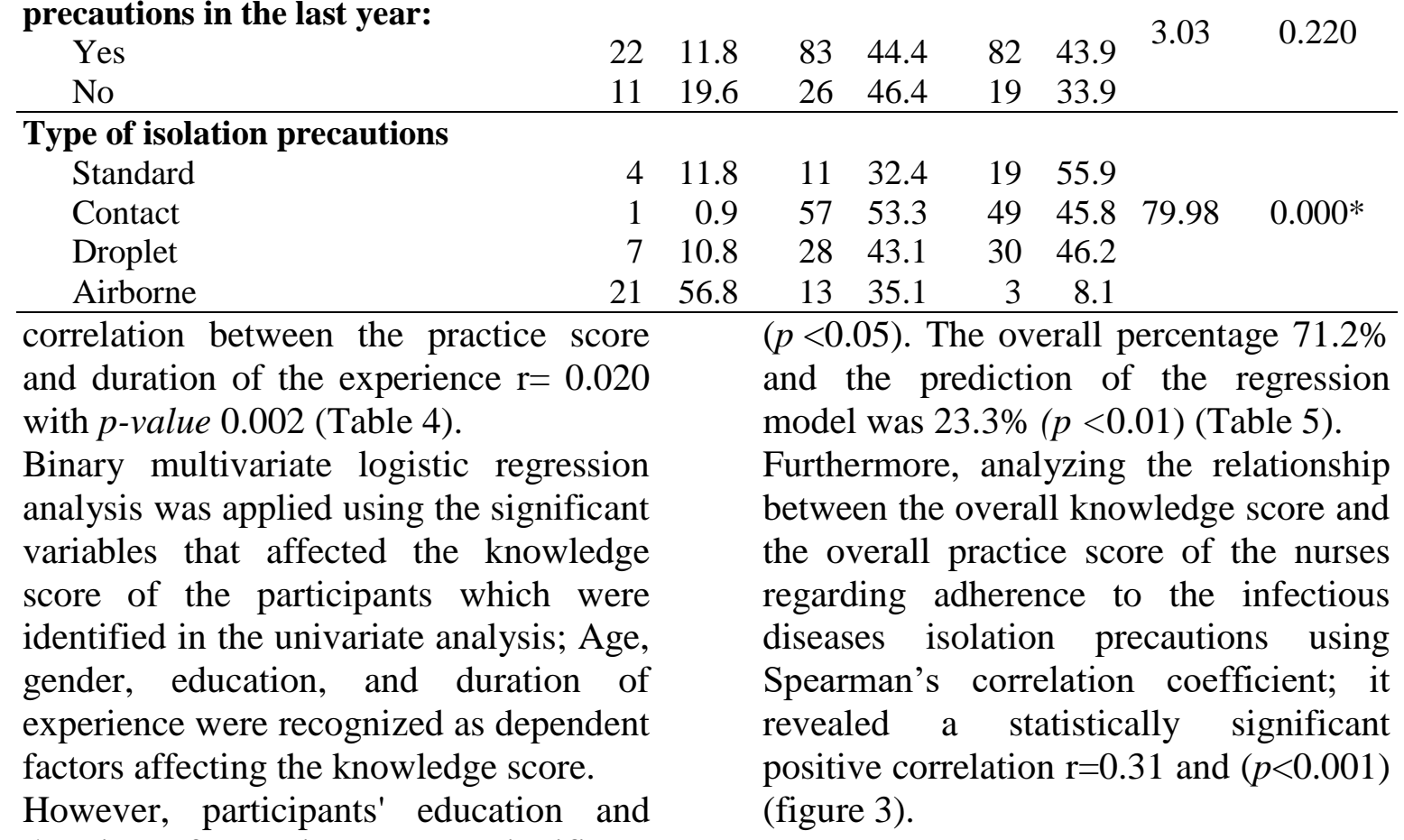

duration of experience were significant predictors for higher knowledge scores

\section{Discussion}


The threat of infectious diseases continues to pose a risk not only in the community but also in healthcare settings. Understanding and implementing isolation precautions are fundamental actions to prevent the spread

Table (4): Correlation between participant nurses' knowledge and practice level with nurses' age and duration of experience

\begin{tabular}{|c|c|c|c|c|c|}
\hline Variables & & $\begin{array}{c}\text { Age } \\
\text { (years) }\end{array}$ & $\begin{array}{l}\text { Duration of } \\
\text { work in the } \\
\text { current hospital }\end{array}$ & $\begin{array}{c}\text { Knowledge } \\
\text { level }\end{array}$ & $\begin{array}{c}\text { Practice } \\
\text { level }\end{array}$ \\
\hline \multirow{2}{*}{ Age (years) } & $r_{p}$ & 1 & $.685^{* *}$ & $.231 * *$ & .090 \\
\hline & $\mathrm{P}$ value & & .000 & .000 & .160 \\
\hline \multirow{2}{*}{$\begin{array}{l}\text { Duration of work in } \\
\text { the current hospital }\end{array}$} & $r_{p}$ & $.685 * *$ & 1 & $.337 * *$ & $.197 * *$ \\
\hline & $P$ value & .000 & & .000 & .002 \\
\hline \multirow{2}{*}{ Knowledge level } & $\mathrm{r}_{\mathrm{p}}$ & $.231 * *$ & $.337 * *$ & 1 & $.302 * *$ \\
\hline & $\mathrm{P}$ value & .000 & .000 & & .000 \\
\hline \multirow{2}{*}{ Practice level } & $\mathrm{r}_{\mathrm{p}}$ & .090 & $.197 * *$ & $.302 * *$ & 1 \\
\hline & $P$ value & .160 & .002 & .000 & \\
\hline
\end{tabular}

**. Correlation is significant at the 0.01 level (2-tailed).

Table (5): Logistic Regression Analysis of Independent Factors Affecting Nurses Knowledge Score

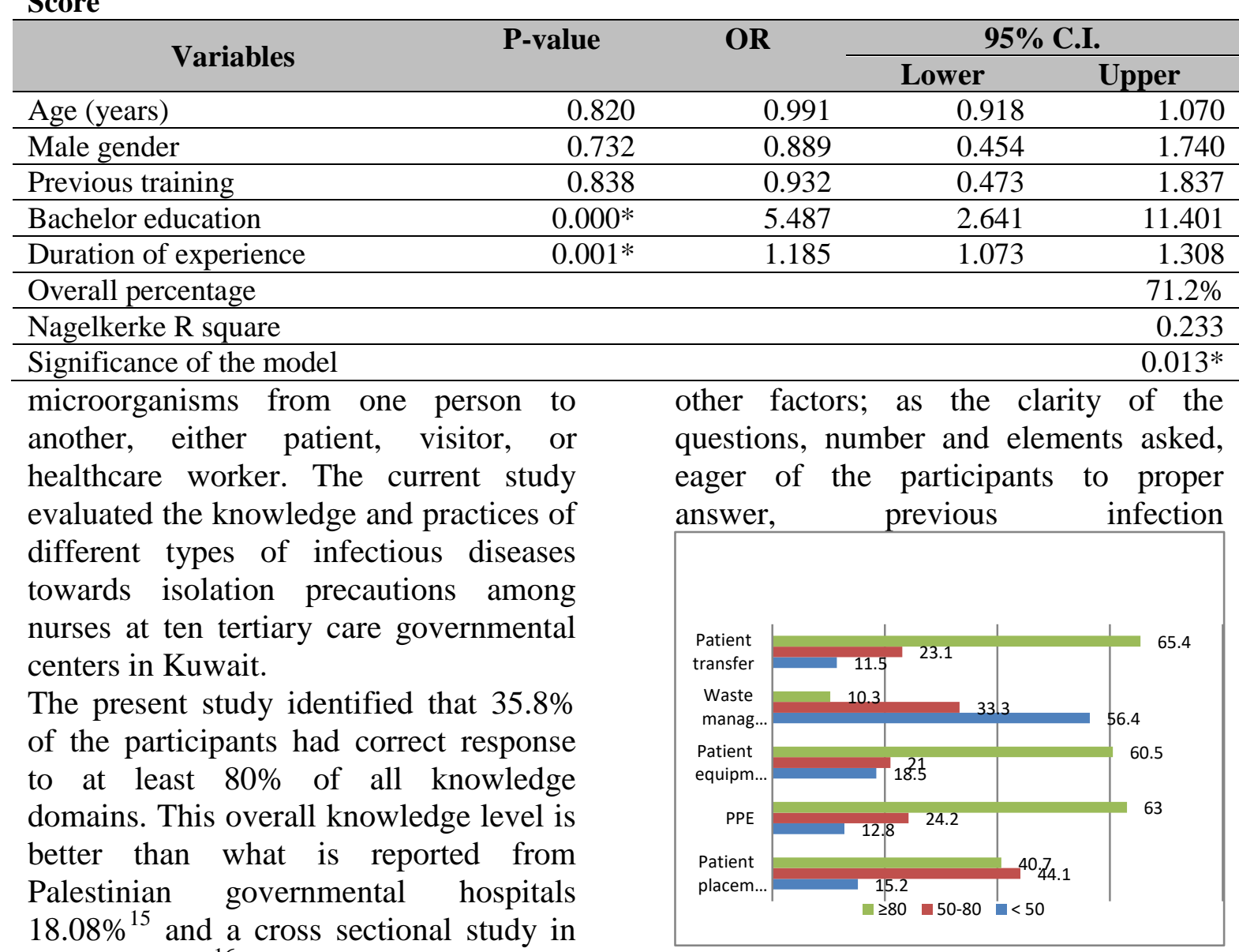

Yemen (4\%). ${ }^{16}$ The discrepancy in the Figure (1): Distribution of The knowledge level recorded is not solely Participant Nurses' Knowledge Domains due to the proper answer percentage in Scores the questionnaire, but it could be due to 
control training received. ${ }^{10,16-18}$ Nevertheless to improve nurse's good knowledge score; additional training using different procedures and approaches is required concentrating on different types of isolation precautions as an alternative to the general training on infection control. ${ }^{10}$

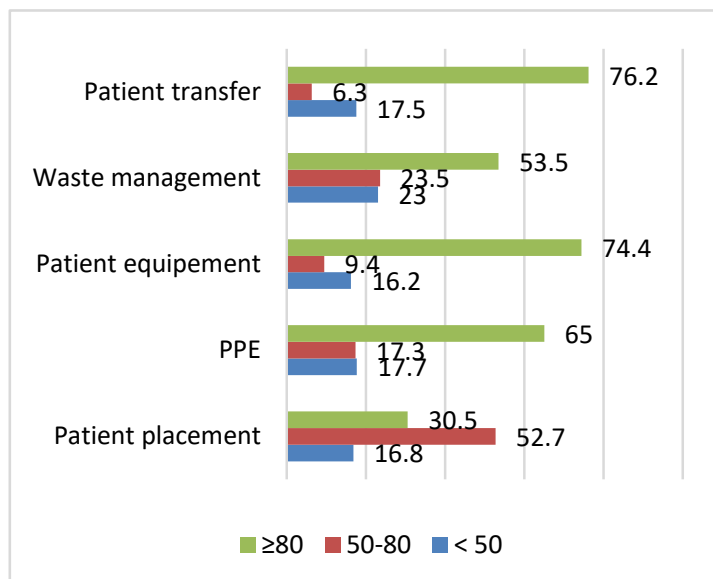

Figure (2): Distribution of The Participant Nurses' Different Practice Domains Scores

Bivariate analysis of the knowledge domains about participants' characteristics, showed a statistical significance difference between knowledge scores in different aspects concerning different age groups. These findings were comparable with those reported from various studies conducted in Iran and Turkey. ${ }^{17,19-20}$

The present study reported that the nurses' knowledge level towards isolation precautions influenced by their gender; females had better knowledge than males. This result was consistent with Motamed et al, who found that, there was a relationship between HCWs' gender and their knowledge. ${ }^{21}$ Unsurprising results of the existing study indicated that nurses' knowledge and their level of education were significantly associated. This finding is concurred with Al Jazairi who documented that, the level of knowledge increased when the level of education has improved too. ${ }^{22}$

Our study demonstrated that, $41.6 \%$ of the studied nurses had a correct practice for at least $80 \%$ of the overall observed isolation precautions domains. This finding was higher than the outcomes found in other research studies; that documented nurses' compliance to appropriate isolation precautions ranged between $(8-26 \%){ }^{10,16-17}$ The variation in the nurses practice towards isolation precautions in the research studies could be due to several factors; like healthcare worker attitude to apply isolation precautions, the infrastructure inclination specially for airborne and to a lesser extent for the droplet isolation precaution, and healthcare worker knowledge for all types and requirement in each isolation precaution. ${ }^{10,17,23-25}$ The inconsistency between the level of knowledge and practice points out the difference between theory in guidelines and real-life practice. ${ }^{16}$

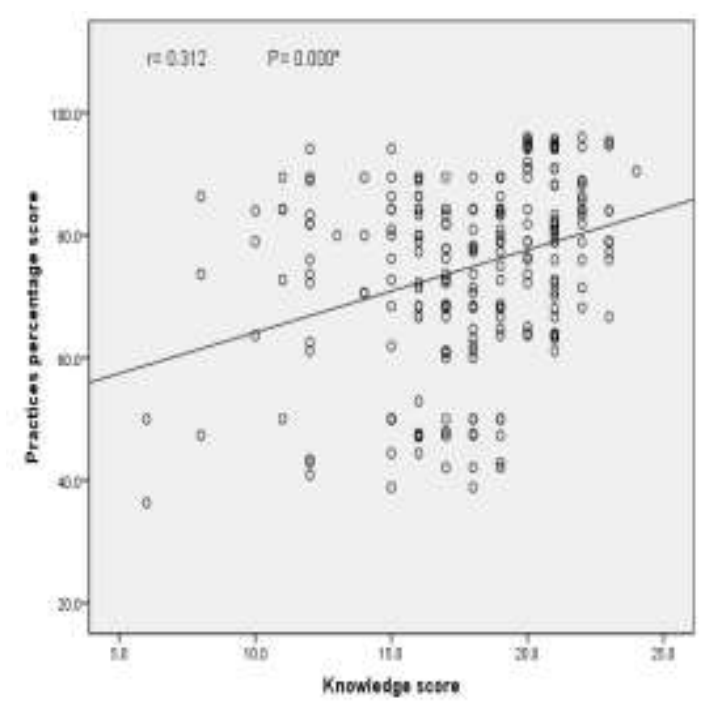

Figure (3): Correlation between Participating Nurses' Knowledge Score and Practice Score

The current investigation identified many factors that, influencing the participants practice score with statistical significance difference; nurses' gender, working unit (ICU vs non ICU), type of isolation and the working experience, these findings were similar to the results described by Arli et al, who concluded positive and significant relationship between the isolation precautions compliance and 
nurses age, education, ICU working and duration of experience. ${ }^{19}$ It is anticipated to see that experience, knowledge that is gained all over the years, continuous training with an emphasis on the weak points will reflect positively on the nurses' practice. ${ }^{18,22}$

Our investigation displayed a positive correlation between the overall knowledge score and the overall practice compliance. This was in favor with the findings of multiple research studies in different countries. ${ }^{17-18,26}$

The majority of the research studies applied a self-administered questionnaire to assess the nurses' knowledge and practice towards isolation precautions and the greater part of them did not describe the significant difference between participants' knowledge and practice scores. In the present research, a self-administered questionnaire was used to evaluate nurses' knowledge in addition to using a direct observation method with a checklist to calculate participants' practice. This method ensures the realistic observation of the practice of the participants under investigation rather than depending on what they report in the questionnaires. ${ }^{27}$

While the weakness of the study is that all study sites were tertiary cares so we cannot generalize the results obtained from this study.

\section{Conclusion}

The studied nurses showed a better practice of isolation precautions than knowledge, yet this level need to surge in order to provide better and safer patient care. The nurses knowledge level was inclined by some variables; age, gender, education, and experience. While their practice score was affected by; gender, work experience and unit of work (ICU vs. non ICU). A significant positive correlation between the overall knowledge score and the overall practice score was found. Customized training and education programs are recommended focusing on different isolation precautions aspects to improve their knowledge and promote their practices.

Acknowledgments: The authors would like to thank all the staff nurses who participated in the current study for their cooperation. The authors are also very grateful to the infection control nurses working in the studied tertiary care centers for their help in data collection.

\section{References}

1. Andre FE, Booy R, Bock HL, et al. Vaccination greatly reduces disease, disability, death and inequity worldwide. Bull World Health Organ. 2008; 86(2):140 6.

2. Baker MG, Barnard LT, Kvalsvig A, et al. Increasing incidence of serious infectious diseases and inequalities in New Zealand: a national epidemiology study. Lancet. 2012; 379(9821): 1112-9. doi: 10.1016/S01406736(11)61780-7. Epub 2012 Feb 20.

3. Ben Fredj M, Belguith SA, Abroug H, et al. Hospitalizations for communicable diseases in a developing country: prevalence and trends-Monastir, Tunisia, 2002-2013. Int J Infect Dis. 2017; 55: 102-8. doi: 10.1016/j.ijid.2017.01.009. Epub 2017 Jan 16.

4. Rocha BA, Trujillo ME, Hidalgo PC, et al. Burden of disease in Nariño, Colombia, 2010. Colomb Med. 2014; 45(3): 96-103.

5. GBD 2013 Mortality and Causes of Death Collaborators. Global, regional, and national age-sex specific all-cause and cause-specific mortality for 240 causes of death, 19902013: a systematic analysis for the Global Burden of Disease Study 2013. Lancet, 2015; 385(9963): 117-71. doi: 10.1016/S0140-6736(14)61682-2.

6. Garner JS. Guidelines for isolation precautions in hospitals. The Hospital Infection Control Practices Advisory Committee. Infect Control Hosp Epidemiol, 1996; 17(1): 53-80.

7. Osuala EO, Oluwatosin OA. Infection control by nurses in selected hospitals in Anambra State, Nigeria. Trop J Med Res 2017; 20:53-60. doi: 10.4103/11190388.198122 .

8. Storr J, Twyman A, Zingg W, et al. Core components for effective infection 
prevention and control programmes: new WHO evidence-based recommendations. Antimicrob Resist Infect Control 2017; 6 (6): 1-18. doi: 10.1186/s13756-016-0149-9. eCollection 2017.

9. Alfouzan W, Dhar R, Albarrag A, et al. The emerging pathogen Candida auris: A focus on the Middle-Eastern countries. J Infect Public Health 2019; 12(4): 451-9. doi: 10.1016/j.jiph.2019.03.009. Epub 2019 Apr 16.

10. Suliman M, Aloush S, AlJezawi M, et al. Knowledge and practices of isolation precautions among nurses in Jordan. Am J Infect Control, 2018; 46 (6): 680-84. doi: 10.1016/j.ajic.2017.09.023. Epub 2017 Nov 3 .

11. Alsahafi AJ, Cheng AC. Knowledge, attitudes and behaviours of healthcare workers in the Kingdom of Saudi Arabia to MERS coronavirus and other emerging infectious diseases. Int J Environ Res Public Health 2016; 6; 13 (12).

12. Eskander HG, Morsy WYM, Elfeky HAA. Intensive care nurses' knowledge \& practices regarding infection control standard precautions at a selected Egyptian cancer hospital. J Educ Prac 2013; 4 (19): 160-174 13. Department of Health and Medical Records. Annual Health Report, 52 edition, Ministry of Health, State of Kuwait, 2015. Available

from: www.moh.gov.kw/Renderers/ShowPd f. $a s h x$ ? Id =5cfd549b-a15c-408bQ7bf8d-

01db46afffd8 (last accessed August 12, 2017).

14. Siegel JD, Rhinehart E, Jackson M, et al. Guideline for Isolation Precautions: Preventing Transmission of Infectious Agents in Healthcare Settings. 2007 Available

from: https://www.cdc.gov/infectioncontrol /guidelines/isolation/index.html(last access September 18, 2019).

15. Fashafsheh I, Ayed A, Eqtait F, et al. Knowledge and practice of nursing staff towards infection control measures in the Palestinian hospitals. J Educ Pract. 2015; 6(4):79-90.

16. Alrubaiee G, Baharom A, Shahar HK, et al. Knowledge and practices of nurses regarding nosocomial infection control measures in private hospitals in Sana'a City, Yemen. Safety in Health, 2017; 3(16): 1-6. doi: 10.1186/s40886-017-0067-4.
17. Mohammadzadeh M, Behnaz F, Parsa S. Knowledge, practice and attitude towards standard isolation precautions in nurses, auxiliary nurses and midwives of Shahid Sadoughi Hospital, Yazd, Iran. Int J Infect Control, 2013; 9 (1): 1-8. doi: 10.3396/ijic.v9i1.005.13.

18. Thu TA, Anh NQ, Chau NQ, et al. Knowledge, Attitude and Practices Regarding Standard and Isolation Precautions among Vietnamese Health Care Workers: A Multicenter Cross-Sectional Survey. Intern Med, 2012; 2(4):1-5. doi: 10.4172/2165-8048.1000115.

19. Arli SK, Bakan AB. Nurses' compliance with isolation precautions and the affecting factors. Appl Nurs Res, 2017; 38: 175-8. doi: 10.1016/j.apnr.2017.10.014. Epub 2017 Oct 16.

20. Erden S, Kahraman BB, Bulut H. Evaluation of compliance of physicians and nurses with isolation precautions in intensive care units. Gümüşhane University Journal of health science, 2015; 4(3): 388-98.

21. Motamed N, Baba Mahmoodi F, Khalilian A, et al. Knowledge and practice of health care worker and medical students towards universal precautions in hospitals in Mazandaran province. East Mediterr Health J, 2006; 12(5):653-661.

22. Al-Jazairi MA. Assessment of nurses knowledge concerning children with cleft lip and cleft palate at pediatric teaching and non-teaching hospitals in Baghdad, master thesis, pediatric Nurses, College of Nursing, Baghdad University, 2007.

23. Reuben FB, Dare AO, Oluseyi AO. Knowledge and Practice of Airborne and Droplet Precautions within the Emergency Departments of Selected Hospitals in Osun State, Nigeria. International Journal of Caring Sciences, 2018; 11(3): 1539 -45.

24. De Bono S, Heling G, Borg MA. Organizational culture and its implications for infection prevention and control in healthcare institutions. J Hosp Infect, 2014; 86. doi: 10.1016/j.jhin.2013.10.007. Epub 2013 Oct 31.

25. Askarian M, McLaws M-L, Meylan M. Knowledge, attitude, and practices related to standard precautions of surgeons and physicians in university-affiliated hospitals of Shiraz, Iran. Int J Infect Dis, 2007; 11: 213-9. Epub 2006 Jul 11. 
26. Batran A, Ayed A, Salameh B, et al. Are standard precautions for hospital-acquired infection among nurses in public sector satisfactory? Arch Med Health Sci, 2018; 6: 223-7. doi: 10.4103/amhs.amhs_84_18.

27. Centers for Disease Control and Prevention. Data collection methods for program evaluation: observation, evaluation briefs, U.S. Department of Health and Human services. USA. 2018. Available from: www.cdc.gov/healthyyouth/evaluatio n/pdf/Q6 brief16.pdf (last accessed August 7 , 